\title{
POSSIBILITY OF ENGLISH LANGUAGE LEARNING THROUGH LITERARY WORKS
}

\author{
Seniha KRASNIQI ${ }^{1}$ \\ Atdhe HYKOLLI ${ }^{2}$ \\ ${ }^{1}$ Assoc. Prof. Dr. University of Prishtina, Faculty of Philology, seniha.krasniqi@uni-pr.edu Orcid ID 0000-0001-9737-8429 \\ ${ }^{2}$ Assoc. Prof. Dr. University of Prishtina, Faculty of Education, atdheh@ hotmail.com Orcid ID:0000-0002-9362-3607
}

Krasniqi, Seniha \& Atdhe Hykolli. "Possibility of English Language Learning Through Literary Works”. ulakbilge, 47 (2020 Mart): s. 490-494. doi: 10.7816/ulakbilge-08-47-08

\begin{abstract}
Being aware of the importance of the English language as the most widely used language of communication in any field, the interest in its learning is not a surprising fact. Hereof, we will discuss the challenges in the English language, respectively foreign learning through literary works, the influence of literary work in language learning, as well as suitability of language knowledge level for inclusion of literary works. Literary works make teachers hesitant in their use in language learning due to the divergence from the traditional pattern of language learning and conventionally structured coursebooks which offer a linear system of learning despite the fact that language learning is non-linear in its nature. The paper simultaneously writes on the importance and influence of the general knowledge and the level of language comprehension in the process of reading a literary material, where it finds the deriving of the connotative and denotative meaning of the literary text depending on these elements. Likewise, it treats the universality of the theme as the element which can include the learner in analogues situations hence leads to an easier connection to the text and cognitive processing of the story, and ultimately the target language.
\end{abstract}

Keywords: language, literary works, coursebook, traditionality, possibility 


\section{Introduction}

The importance of the English language is undeniable in the world today. The interest of learners is growing at an immense pace. The interest is sometimes for the professional need and occasionally for satisfaction. Likewise, the learning is sometimes followed with anxiety and sometimes excitement. At this point the role of the teacher and organization of his classroom is crucial, where he carries the accountability of stimulating and motivating his students, hence developing an interest in English language learning. Every teacher strives to accomplish the utmost success in this regard. Thus, they "leave no stone unturned" to make their classroom communicative, practical, efficient and fun. Hereof, they define their objectives and approach in achieving them.

Regular coursebooks and routine activities though suitable may deem learning ponderous. Therefore, making alterations makes the class furbish. One of the most efficient approaches is changing the atmosphere of the classroom. This can be done by incorporating literature in English language learning. Within this, the teacher should encourage learners for interaction, cooperation, and reflection in order to induce their motivation and lessen their anxiety. While the teacher should set achievable goals and pursue the progress, the students should be aware of the tasks and objectives set by the teacher in order to constructively accept the new approach of introduced literature in language learning.

As literature is the mirror of a society which reflects all the values, customs, morals, traditions, people and their lifestyle, it is welcoming for the completion of the language learning, attributing to the learning of its cultural and social background beside its language. This kind of content and variety of language affiliates the le arners to the world of the target language and the mindset of its nation. Pertain to the direct activation of the learners, literature actuates learners' imagination and critical thinking, creating a further connection to the literary material, respectfully language learning through literature. Moreover, with literature's involving concrete situations, it reveals a broad world to the learner with the various experiences and occurrences. These kinds of developments acquaint the learner with the vocabulary of ordinary circumstances and natural language, the vocabulary which can, in fact, be used in their world and activities. The idea of this outcome increases learners' interest in literary works as complementary material in language learning.

\section{Challenges in language learning and literature combination}

Literary material is tended to be avoided due to its not fitting into a customary pattern of language learning. People's preference leans towards the traditional, the known things as most of us are a creature of habits. Even in the cases when we seek new experiences, it is the experience, we saw that someone else lived and had. Nevertheless, there are free spirits who are independent and distanced from the conventional. With their eccentric perception, their not fitting the traditional structure makes them "distinct", hence troubling in many senses. Teaching does not tolerate troubles or chaos that comes from a non-controlled style of learning, respectfully learning languages, this is the reason why stability is kept for centuries through structured methods and books. These structured books are designed by models that cannot surprise the teacher nor the learners. They go step by step and that in the known steps, hence even if you change the coursebook you are not far from the familiar structure. This happens in English language learning as well. If you learn English at school or private course you are prepared for the standard learning style and standard coursebook model. Moreover, the coursebooks are structured in a single model. This is the issue that concerns the learners who do not specifically fit the level nor that type of learning. Hence, more advanced students will have to halt, and the less advanced students will have to accelerate their learning process, but the books will keep their structure and the "one-size-fits-all" books will remain.

It is not everything black, nor are the coursebooks source of regression. They are structured with a logical approach and sustain learning in a reasonable manner. Although language learning does not include linearity in its nature, the coursebooks maintain a kind of linear model of learning which represent standard, step by step introduction of information. This kind of structure constrains the learner and creates an invisible box within which he can move and act. Having a linear introduction of the material will force the learner to linear usage of the language and will make him a subject of restricted development.

Otherwise, introducing literature to language learning will haul some unconventionality into the classroom. It will introduce a nonlinear learning style. Nonlinear learning is "Learning that has been designed to ensure students can shape their learning through self-organization and self-organized criticality" (Feist and Reid, 2018: 88). Or "A system in which learners are provided with a variety of options, they choose their own path, different learners can follow different paths, and the outcomes are emergent and cannot be foretold (Burage and Pelton, 2009: 147) ." 
with a literary work the learner can focus to any part of the material. He can personalize the learning and steer his path. Nonlinear learning seems like a puzzle to put pieces into place and the person will discover himself where to put what. Initial disordered pieces of the puzzle, hence unorganized situation dissuade teachers due to the messy class. And the unknown results or direction that the class might take create a sense of unpreparedness. This is another reason why teachers withdraw from a puzzle that derives from literary works in language learning.

Furthermore, the teachers themselves are a product of linear learning throughout their academic careers. The textbooks they have now as teachers are similar to what they used as students. But as Dudley puts it in his books on ESL teaching, teachers are "Materials Provider" thus they are in charge of manipulating their classes, bringing new material and hold unconventional class which would be equally successful as linear, if not more, as, "performer constraints refer to the structural and functional aspects of the learner; environment constraints incorporate the physical and the social-cultural environment; and rules of a game; and equipment and goals of the task can be categorized as task constraints" (Davids et al., 2008). But with the nonlinear le arning which incorporates literary work in the language classes the learner can direct his focus, he can set the rules of the game and can minimize the constraints, all unlike the possibilities he has while using a textbook.

“...human learning is nonlinear in nature" (Chow \& Atencio, 2012, Tan, Chow, \& Davids, 2012, retrieved from Jia Yi Chow, 2013: 470), this can be the situation with language learning as well. After introduced with the basics of a foreign language. More precisely after the intermediate acquiring, the learner can integrate literature into his learning. Through literary work, his language learning can be broader and closer to human issues.

Literary works are one of the most effective vehicles of linguistic and cultural experience in second language reading. Assuming that the readers have a fair command of the basic structures of the target language -its grammar and vocabularypoems, novels and short stories represent a multi-faceted source to expand their linguistic skills. Moreover, exposure to the foreign language through its literature is a stimulating and more authentic way to deal with the cultural and historical fact ors involved in the whole process of foreign language reading (Sanchez, 1993: 63).

Hence trough the exposure to the literature of the target language, the learner will not only learn its linguistics but will be introduced to its cultural and historical background, the information which will further connect the learner to the target language when introduced to it in the depth through these literary texts.

\section{Influence of literary work in language learning}

According to the Rosenblatt "both reader and text are seen as two separate entities acting upon one another, but without realizing any 'organic' transformation as a result of their encounter" (retrieved from Sanchez, 1993. p.64). This relationship between the text and the readerllearner is interactive and acts upon each other with various effects. Nevertheless, while the text's act upon the reader is bigger, the reader's reaction to the text is multiple. The reader can react to numerous degrees and levels due to his background. His reaction and comprehension of the text depend on his domination of the foreign language as well as general knowledge. While language knowledge helps the learner in the comprehension of the denotative meaning of the material, the general knowledge helps in the comprehension of the connotative meaning of the developments in the story which simultaneously help in fathoming the unknown words based on the contexts, the context which we understood due to our general background.

The capacity of general knowledge or fitting of the literary text to our subject of interest can play the role of connector between the learner and the material. The closeness with the text will raise the interest and comprehension which will ultimately lead to the curiosity and interest in comprehension even the remaining unfamiliar parts and words. Hence, selective comprehension which is due to the learner's knowledge background would develop into the unselective conception of the material.

The amount of comprehending the literary work affects the magnitude of learners reaction, nevertheless, despite the extent of the reaction, he will anyhow be introduced to the target language in a more casual manner and under more regular circumstances which represent "real life" as according to Common European Framework of Reference for Languages, language is best learned through "real-life situations". "Real-life situations" are experiences not remote to learner's experience or experience of his acquaintances. The importance of this proximity is proven with people's interest in literary texts with universal themes.

The best literary themes explore human nature on a universal level. It's no surprise, then, that multiple books may share the same central idea. Each of the following popular theme examples reveals the human condition and offers readers food for thought long after the story is finished (Atwood, 2019: 35).

Hence, Atwood continues describing her own writing experience emphasizing the importance of the readers' 
believing in your literary work, respectfully the story, despite the fact that they are aware of its fictional character. These stories morally feed us; teach us the good and bad, the courage, the power of love, vengeance, ungratefulness, and all human dilemmas. What makes stories captivating is their occurrence sometime, somewhere. It happened once to someone, moreover, it happened multiple times and it is going to continue happening for as long as the universe exists in one or another shape or form but with its universality where it will relate to the abovementioned themes. This possibility of experiencing these universal themes attracts the reader due to his own distant or close experience or possibility of living analogues situations. Thus, they relate, easily comprehend and create an opinion on the plot developments, which lead to cognitive processing of the story, and the target language.

Reading a literary work or any other written material is a receptive skill through which we receive data, nevertheless, it is a skill which activates our previous knowledge of the language and gathers material and information which prepare us for productive skills, that enable our own production in the foreign language according to our necessities.

\section{Suitability of language knowledge level for inclusion of literary works}

Incorporation of literary material into language teaching which can be complementary material if not the complete substitution is suitable to be started in the B2 level where the learner is an independent user of the target language at the vantage point rather than the border.

According to the Common European Framework of Reference for Language, a learner of this level on the global scale,

Can understand the main ideas of complex text on both concrete and abstract topics, including technical discussions in his/her field of specialization. Can interact with a degree of fluency and spontaneity that makes regular interaction with native speakers quite possible without strain for either party. Can produce clear, detailed text on a wide range of subjects and explain a viewpoint on a topical issue giving the advantages and independent disadvantages of various options (CEFR, 2001:24).

According to the Common European Framework of Reference for Languages, self-assessment grid in understanding, respectfully reading, the learners of this particular level "can read articles and reports concerned with contemporary problems in which the writers adopt particular attitudes or viewpoints. Can understand contemporary literary prose" (CEFR, 2001, 24). Using this receptive skill with the contemporary literary prose for the target language development, the learner can provide knowledge for the productive skills of speaking and writing. Hence, regarding the spoken interaction, the learner can be fluent and spontaneous in discussing familiar subjects. Concerning spoken production, he can produce strong explanations in his area of interest. On the other hand, related to the writing skill he can easily express his supporting and opposing views on the subject of interest (CEFR, 2001: 27).

While it remains the truth that people's objective even in language learning differs from person to person, the most important thing in language learning is simply interaction and communication. Nevertheless, we cannot come to interacting and communicating points until we gather information, and this can be done through literary works with all their vast content which were once used as language learning material.

According to Widdowson (1982), although literature once played a significant role in language study, its prominence faded as linguistics became the focal point of language programs. Linguists such as Topping (1968) argue that literature should be excluded from the foreign language curriculum because of its structural complexity, lack of conformity to standard grammatical rules, and remote control perspective. In other words, these linguists believe that literature does not contribute to foreign language students' practical goal of achieving linguistic proficiency (Turker, 1991: 300).

English language learners should not be denied the opportunity of learning language through literature, especially those in the previously mentioned level who solidly mastered the linguistic rules of the language and now are at the phase of developing their vocabulary and cultural and historical background of the language which are complementary elements of any foreign language. Where likewise, learners of this level are suitable to comprehend the structural complexity and grammatical constructions used in literary works.

\section{Conclusion}

Learning the English language, respectively any other foreign language is accompanied by both anxiety and excitement depending on the learner and purpose. Sustainability of the interest that learners feel in learning English as a foreign language is the duty of the teacher. One of the choices in changing the routine style of learning can be 
an incorporation of literature in language learning. The issue of literature inclusion into language learning has provoked many reactions on both sides of promoting the idea as being effective for the emotional stimulation of the students' imagination and critical skills, to the opposing ideas due to the language complexity used in the literary works. This paper numbered the importance of the literature in language learning as a mundus which reflects all the values, customs, morals, traditions, people and their lifestyle, connecting the learner to the world of English language nation. Nevertheless, we could not avoid the reality of people's consuetude to the traditional form of language learning. Traditional means stability. Conventional means certainty and that is the preference of many who are not fond of challenging the outcomes of their work. Hence, there are the sustainability criteria that include structured coursebooks as an absolute method of learning for centuries. Despite the fact that the paper strives to promote language learning through literature, we should not avoid the success of coursebooks which hold linearity and gradual introduction of information in themselves. However, the guidance in their content with the linear nature limits the learner to their information. Language learning in itself is nonlinear. This is the reason why the paper supported the incorporation of literature in language learning as the learner can control his path. This kind of control can be given following the intermediate level of learner's language knowledge where now he can closely approach human concerns through a poem, short story, novel, or drama. Reading the literary texts, the learner is subject to its influence which stirs his reaction. Learners' reaction depends on the level of his comprehension of the text and general knowledge. Under favor of his general knowledge and comprehension level of the foreign language, the learner will derive the denotative and connotative meaning of the text where simultaneously from the selective comprehension of the text will pass to the unselective conception of the material through the awakened curiosity and interest. Within this context, the subjects of interest are generally universal themes which do not change through centuries and hold their position of importance despite the social status and period of time. The universality of the theme raises the captivation of the learner due to the fact that these issues happened and are going to happen in the future as they are an integral part of humanity and ultimately appealing for the learner. Suitability of inclusion of the literary material into language learning is considered to be B2 level as pursuant to Common European Framework of Reference for Languages where learners of this level are able to percept "complex text of either concrete and abstract topics" leading the same to constructing and expressing his own perspective in the same complexity. Hence, despite the defiant views, literary works should be involved in language learning for more independent learning and more extended vision, as well as for the fact that it represents complementary element with all its vocabulary, cultural and historical background it includes.

\section{Kaynaklar}

Atwood, Margaret. “Teaching Creative Writing” Masterclass, Trinity University, USA, 2019, retrieved from https://www.masterclass.com/articles/the-complete-guide-to-narrative-theme-in-literature-definition-examples-and-writing-howto\#what-is-a-literary-theme

Burage, Peter. \& Pelton, Leslee Francis, “The Beam Analysis Tool (BAT)”, University of Victoria, Canada, 2009

“Common European Framework of reference for Languages: Learning, Teaching, Assessment”, Council of Europe, Language Policy Unit, Strasburg, 2001 retrieved from www.coe.int/lang-CEFR

Feist, David. \& Reid, Doug. "Technology and Teaching: Technology and Student-Centered Pedagogy in 21st Century Classrooms", University of Dakota, USA, 2018

Renshaw, Ian. Chow, Jia Yi. Davids, Keith \& Hammond, John. “A constraints-led perspective to understanding skill acquisition and game play: a basis for integration of motor learning theory and physical education praxis?", Physical Education and Sport Pedagogy Journal, Vol.15, Routledge, London, 2010

Sanchez, Maria. "Reading literary works in a second language. Transaction and interaction", Filologia y Linguistica XIX, Barcelona, 1993

Turker, Faruk. “Using “Literature” in Language Teaching”, Hacettepe Universitesi Egitim Fakultesi Dergisi ,Vol. 6, Ankara, 1991 